\title{
Cardiac standstill and circulatory flow arrest in surgical treatment of intracranial aneurysms: a historical review
}

\author{
James M. Wright, M.D., ${ }^{1}$ Christina L. Huang, M.D., ${ }^{2}$ Rahul Sharma, B.A., ${ }^{3}$ \\ Sunil Manjila, M.D., ${ }^{1}$ Feng Xu, M.D., ${ }^{1,5}$ Barbara DabB, M.D., ${ }^{4}$ \\ and Nicholas C. Bambakidis, M.D. ${ }^{1}$ \\ ${ }^{1}$ Department of Neurological Surgery, The Neurological Institute, ${ }^{4}$ Department of Anesthesiology, \\ University Hospitals Case Medical Center, Cleveland, Ohio; ${ }^{2}$ Department of Neurosurgery, University of \\ Southern California; ${ }^{3}$ The Commonwealth Medical College, Scranton, Pennsylvania; and ${ }^{5}$ Department of \\ Neurosurgery, Huashan Hospital, Shanghai Medical College, Fudan University, Shanghai, China
}

Since the first surgery for an intracranial aneurysm in 1931, neurological surgeons have long strived to determine the optimal methods of surgical correction. Significant challenges of aneurysm clipping include intraoperative rupture and complex dome morphology. Hypothermia, cardiopulmonary bypass, pharmacologically induced hypotension, and cardiac standstill are a few of the methodologies historically and currently employed in the management of these issues. In the 1980s, significant advances in pharmacology and anesthesiology led to the use of agents such as adenosine for chemically induced hypotension and eventually complete circulatory arrest. Since the institution of the use of these agents, the traditional methods of circulatory arrest under conditions of hypothermia and cardiopulmonary bypass have fallen out of favor. However, there still exists a subset of technically difficult aneurysms for which cardiac standstill, both chemical and hypothermic, remains a viable therapeutic option. In this paper, the authors describe the history of cardiac standstill by both hypothermic and chemically induced means as well as provide examples in which these techniques are still necessary.

(http://thejns.org/doi/abs/10.3171/2014.2.FOCUS13554)

KEY WORDS • aneurysm • circulatory arrest • cardiac standstill

$\mathrm{T}$ THE current mainstays of the treatment of aneurysms are surgical clip placement and endovascular coil embolization. However, despite numerous technological advances in both fields, there remains a subset of aneurysms that prove exceedingly difficult to treat. These are often very large, deep in location, and may have intricate anatomy with respect to their proximity and relation to critical vascular structures. For these technically difficult lesions, a number of strategies have been employed, including carotid artery ligation, induced hypotension, and chemical and hypothermic circulatory flow arrest. The premise of these strategies is to create a temporary reduction in blood flow, which ultimately leads to a softening of the vessel wall and relaxation of the aneurysm dome, which theoretically decreases the risk of intraoperative rupture. While the concept is relatively straightforward, the execution has proven to be exceedingly complex and may lead to less than favorable outcomes. The use of cardiac standstill has fallen into and out of favor for the surgical management of complex cerebral aneurysms over the years, dependent on new advances in the fields of both anesthesia and neurosurgery. In this paper, the authors outline a brief review of the history of the use of cardiac standstill and circulatory flow arrest, both hypothermic and chemical, for the surgical treatment of intracranial aneurysms.

\section{Early Pioneers}

On April 22, 1931, Dr. Norman McComish Dott, Britain's first surgeon solely dedicated to the practice of neurosurgery, performed the first intracranial surgery for the management of a ruptured cerebral aneurysm. A pioneer of early surgical techniques for the management of ruptured aneurysms, Dott described and implemented various techniques for their treatment, including wrapping and carotid ligation. He was the first surgeon to perform permanent internal carotid artery ligation; he undertook the procedure in an initial group of 8 patients, 6 of whom were proven to have internal carotid artery aneurysms on angiography - a newly minted technique at that time. He was also one of the first neurosurgeons to observe that the relative risk of recurrent aneurysm rupture was an indication to proceed with surgical treatment (Fig. 1). ${ }^{21}$

The next two decades saw remarkable strides in 


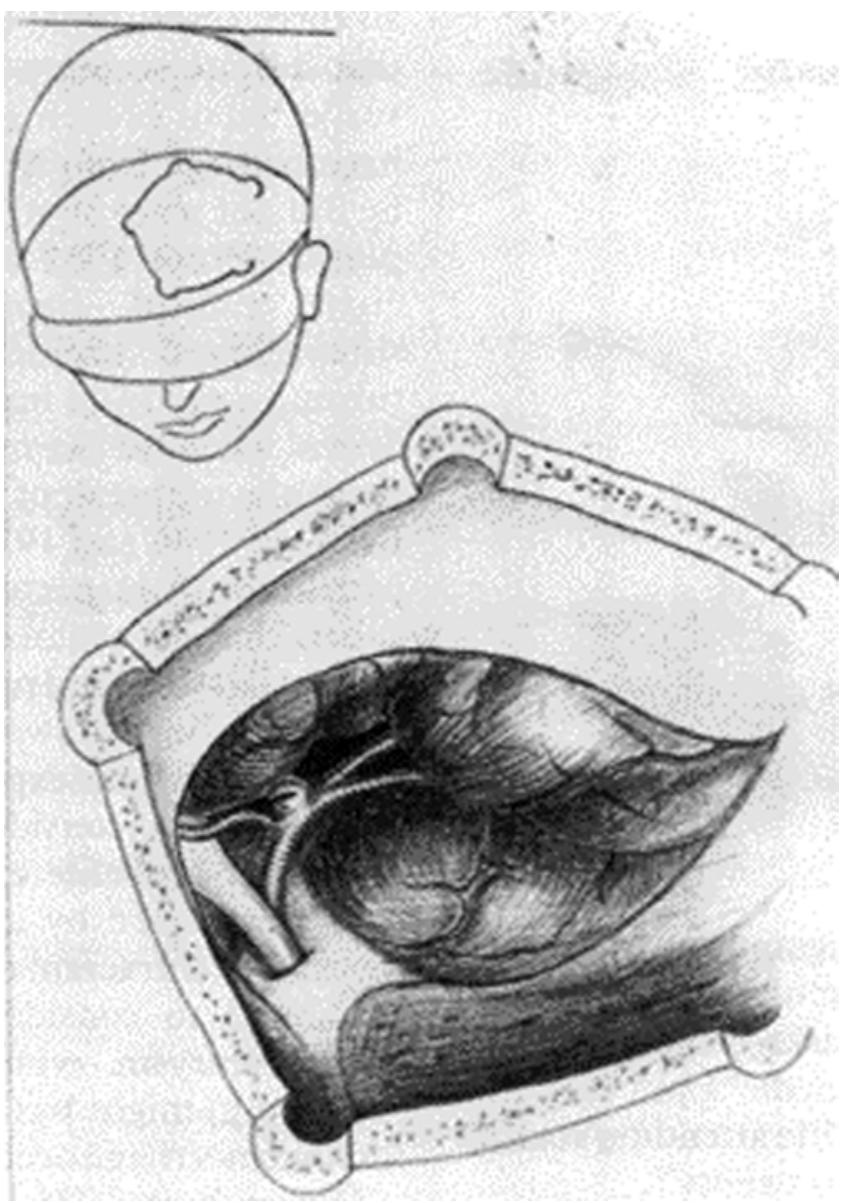

FIG. 1. Original drawing by Dr. Norman Dott of the first surgery performed for intracranial aneurysm repair. Through a left frontal flap, the proximal middle cerebral artery aneurysm was exposed and wrapped with muscle. Reproduced with permission from Todd et al: $J$ Neurol Neurosurg Psychiatry 53:455-458, 1990.

the field of microvascular neurosurgery. Beginning in the early $1940 \mathrm{~s}$, research into the use of hypothermia for cerebrovascular surgery was conducted by Harry Botterell and William Lougheed. Lougheed was instrumental in the development of early hypothermic studies for cerebral surgery. Most of the research conducted by Lougheed was completed in the 1940s and early 1950s in the laboratory of Dr. William Sweet, the third chairman of the Department of Neurosurgery at the Massachusetts General Hospital. After first completing extensive physiological studies of hypothermia in dogs, Lougheed joined Sweet and J. C. White, former chairman of neurosurgery at the hospital, in performing two operations in human subjects under hypothermic conditions. Lougheed had previously demonstrated in animals that the cerebroprotective effect of hypothermia in the setting of anoxia occurred due to reduced rates of neuronal cellular metabolism and oxygen demand, with little to no clinical or pathological evidence that an anoxic insult had occurred (Fig. 2). ${ }^{11,12}$ The animals were monitored with continuous electrocardiogram and electroencephalogram and were found to have no permanent electroencephalographic or electrocardiograhic changes manifesting during or after

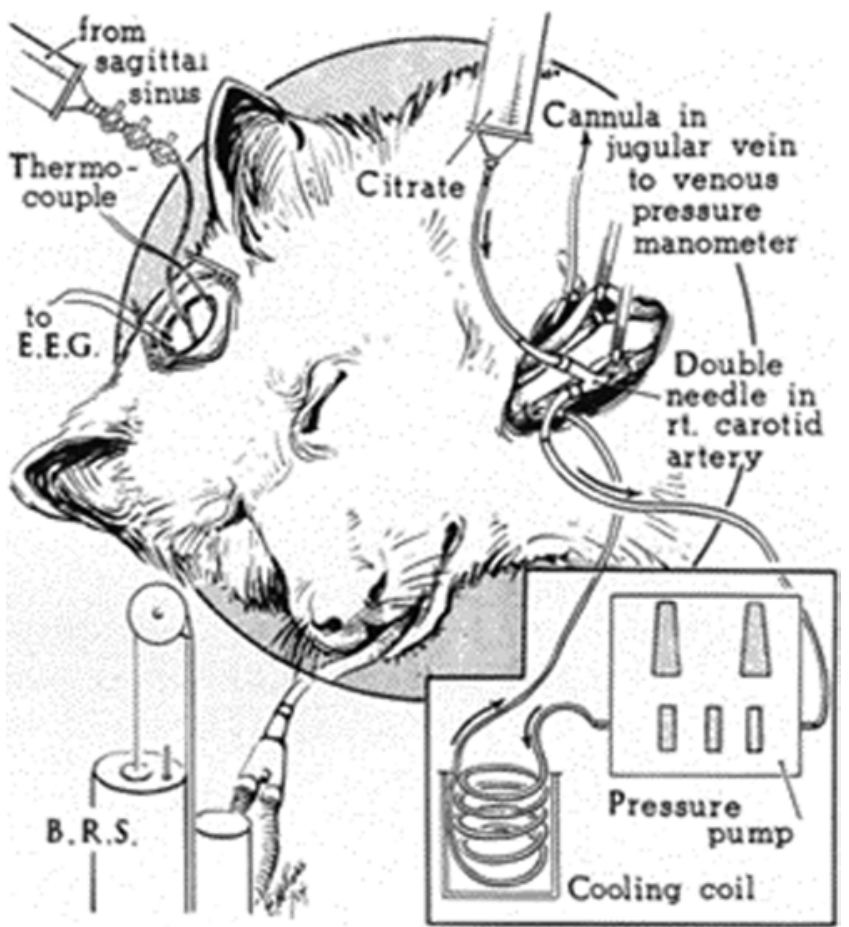

FIG. 2. Original drawing by Lougheed demonstrating an early hypothermic-anoxic study on a dog. Depiction shows the " $Y$ " cannula in the right common carotid artery (CCA) and bulldog clamps on the left CCA and both vertebral arteries. Blood from the cerebral circulation was passed through an ice-water bath and cooled to $9^{\circ}-12^{\circ} \mathrm{C}$, thereby lowering the brain temperature to $20^{\circ} \mathrm{C}$ within $15-20$ minutes. A thermocoupler inserted directly into the cerebral hemisphere measured brain temperatures. Reproduced with permission from Lougheed and Kahn: $J$ Neurosurg 12:226-239, 1955. BRS = breathing regulation system; E.E.G. = electroencephalograph.

a hypothermic insult. These data were used to further guide the determination of adequate and safe temperatures at which to proceed with the first intracranial surgeries under hypothermic conditions (Fig. 3). ${ }^{12}$

The first case of circulatory arrest for the treatment of a cerebrovascular lesion occurred in 1955 in a 17-yearold male who had a large interhemispheric arteriovenous malformation with recurrent bleeding. Preoperative angiographic evidence demonstrated development of new vascular collateral vessels feeding the lesion. A "bloodless field" was desired for this case and all 4 major cerebral arteries were occluded intermittently for a total time of occlusion of 47 minutes. Immediately following the procedure, the patient was alert and communicating but with a new partial right hemiplegia, attributed to retraction. On postoperative Day 4, he experienced rapid neurological decline and ultimately death. Upon autopsy, a right vertebral artery thrombosis was discovered and determined to have resulted from trauma by occlusion of the vessel during the procedure. ${ }^{12}$

Three years later, in 1958, Botterell and colleagues published the first large case series detailing outcomes of patients who underwent surgical treatment of ruptured cerebral aneurysms at Toronto General Hospital under hypothermic conditions with cerebral artery occlusion. Seventy-three patients were treated by surgical clipping 


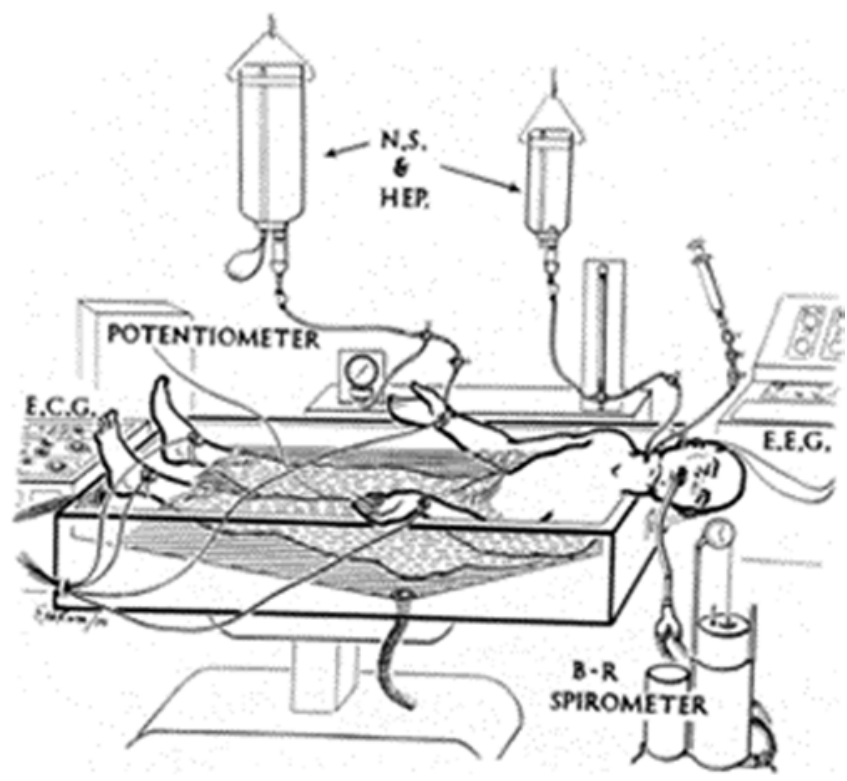

FIG. 3. Representation of a patient in a hypothermic bath with the right radial artery cannulated for blood pressure monitoring. The jugular vein is connected to a manometer. $B-R=$ breathing regulator; E.C.G. = electrocardiograph; HEP. = heparin; N.S. = normal saline. Reproduced with permission from Lougheed et al: J Neurosurg 12:240-255, 1955.

with carotid and/or vertebral artery occlusion under hypothermic conditions. Fifty patients had excellent or good outcomes based on the authors' criteria. Initially in the case series, the surgeons occluded the cervical vessels only if intraoperative hemorrhage occurred. Over the course of the study, they began to observe the utility of occlusion of the common carotid artery immediately before clip ligation or ligature. This method of proximal occlusion reduced tension in the aneurysmal sac and aided in the prevention of intraoperative rupture during attempted ligation or clip placement. ${ }^{3}$ It was the relative success in this study of hypothermia in conjunction with temporary proximal arterial occlusion that subsequently led to increased use of these two techniques for the surgical treatment of aneurysms.

\section{Hypothermic Circulatory Flow Arrest}

By the early 1950s, cardiac surgeons had pioneered the use of hypothermia for cerebral protection during extracorporeal circulation and circulatory arrest for cardiac valve repair. ${ }^{5,19}$ It was during this period when many neurological surgeons began to experiment with hypothermia for cranial surgery in patients. In 1963, Charles Drake, chairman of the Department of Surgery at Western Ontario, presented a series in which he adopted these methodologies for treatment of intracranial aneurysms (Fig. 4). He combined hypothermia with cardiopulmonary bypass in a series of 10 patients who required clipping of particularly complicated aneurysms. As core body temperatures approached $15^{\circ}-18^{\circ} \mathrm{C}$, aneurysm exposure was performed under low rates of circulatory flow. Once exposed, final dissection and ligation was performed under complete circulatory arrest, with periods of total arrest ranging from 2 to 18 minutes. The

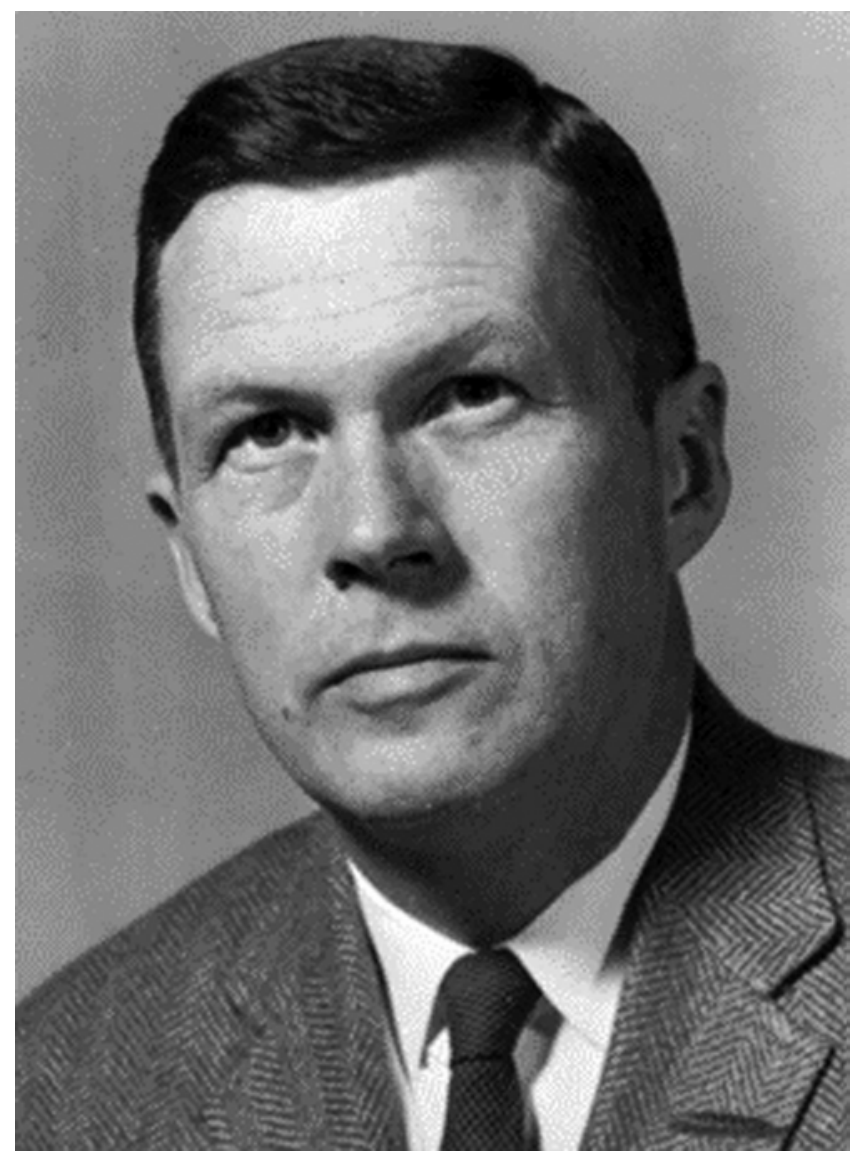

FIG. 4. Portrait of Charles Drake in 1972. Courtesy of University of Western Ontario Archives.

patients were then warmed with reinstitution of cardiac activity and circulatory flow. Drake noted the difficulties of the warming phase due to the significant bleeding incurred at this phase of the operation. ${ }^{4}$ Drake found it particularly disappointing that, although the surgery was technically easier to perform, the use of hypothermia did not aid in the prevention of secondary complications of arterial spasm and ischemic brain injury commonly seen in the setting of ruptured aneurysms, ${ }^{4}$ ultimately leading him to conclude that these techniques were indicated only for the treatment of particularly difficult aneurysms (Figs. 5 and 6 ).

\section{Open-Chest Circulatory Arrest in Aneurysm Surgery}

Hypothermia $\left(12^{\circ}-14^{\circ} \mathrm{C}\right.$ or $\left.53.6^{\circ}-57.2^{\circ} \mathrm{F}\right)$ alone had not been shown to improve survival rates in aneurysm surgery, and defibrillation was difficult with a cold heart. The mandatory use of anticoagulants had made extracorporeal bypass procedures risky, but the development of modified Drew techniques for regional perfusion and oxygenation had given impetus for vascular neurosurgeons to try circulatory arrest in aneurysm surgery. In 1967, Housepian and colleagues reported a successful treatment of a basilar artery aneurysm utilizing a method of open-chest circulatory arrest wherein a midline ster- 


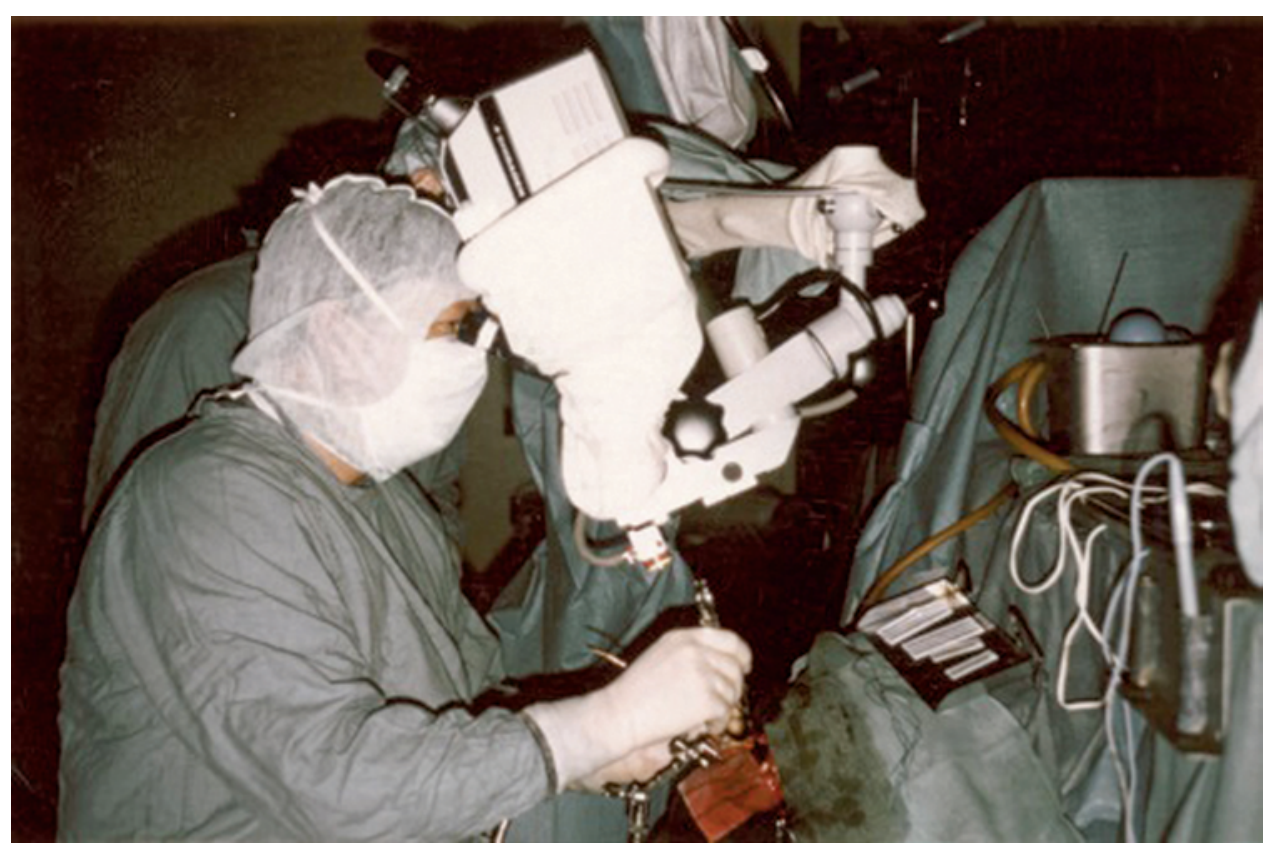

FIG. 5. Intraoperative photograph of Dr. Charles Drake performing aneurysm repair in 1972. Courtesy of University of Western Ontario Archives.

notomy was performed for cardiac access and ventricular fibrillation manually induced for cardiac standstill under hypothermia (achieved via Thermorite blankets; lowest temperature $29.5^{\circ} \mathrm{C}$ ). In this case, ventricular fibrillation was induced by direct electrical stimulation of the left ventricle. The period of circulatory arrest was maintained for approximately 4 minutes and followed by 60 seconds of manual systole with peripheral blood pressure of 60 $\mathrm{mm} \mathrm{Hg}$, which allowed for complete occlusion of the large aneurysmal sac along with the major feeding vessel for a large arteriovenous malformation. The authors concluded that circulatory arrest proved to be a life-saving adjunct in this case and could be further applied where serious hemorrhage might not be easily controlled. The authors described advantages of the open-chest method

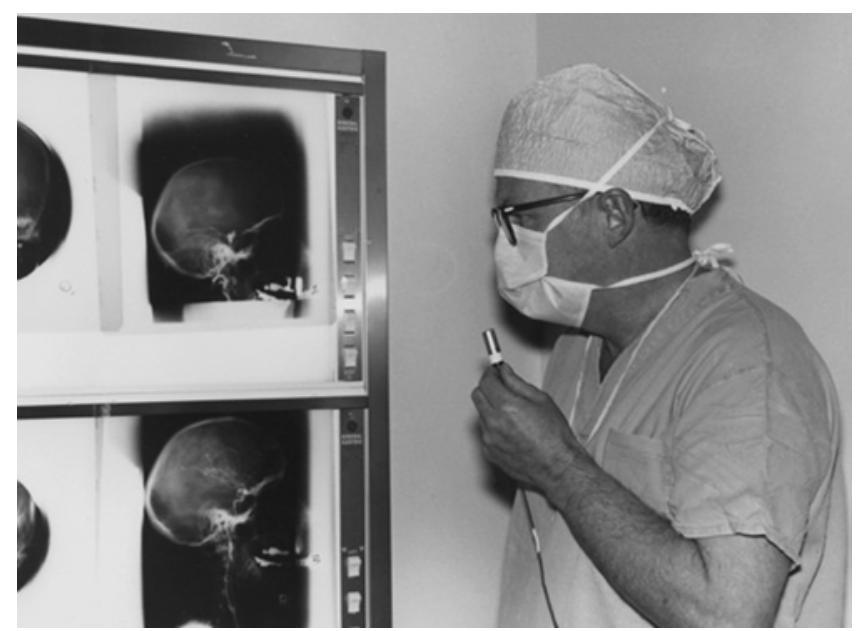

FIG. 6. Photograph of Dr. Charles Drake dictating procedural notes following repair of an intracranial aneurysm. Courtesy of University of Western Ontario Archives. of circulatory arrest, including allowing for elective periods of perfusion by manual systole without the risks of profound hypothermia, clotting abnormalities, postoperative hemorrhage, swelling, or gastric bleeding. ${ }^{9}$

Following this initial case, Aaron Gissen of the Neurological Institute of New York went on to describe 5 more cases treated via the open-chest method under hypothermic conditions with electrically induced ventricular fibrillation and circulatory flow arrest. Gissen and colleagues also determined that circulatory arrest with intermittent manual cardiac massage provided for excellent surgical conditions for hemostatic clipping of infratentorial aneurysms. The authors concluded after this small series of 5 patients that the rates of cardiovascular complications following repeated episodes of circulatory flow arrest were low and acceptable, even in patients with preexisting cardiac conditions. The authors went on to emphasize that, with the use of hypothermia, body temperature gradients should be reversed and the patient should be undergoing rewarming at the time of circulatory arrest if the need for rapid defibrillation were to arise. The authors also advised that tracheostomy be routinely performed in the immediate postoperative period to facilitate respiratory care in these patients. ${ }^{6}$ They had improved intraoperative monitoring of arterial blood gases (Astrup method for determining metabolic acidosis) and continuous intraarterial blood pressure monitoring (using pneumatic manometer unaffected by surgical cautery).

This technique was further examined in 1974 by McMurtry and colleagues ${ }^{15}$ in a series of 12 patients who underwent moderate hypothermia, a temporal craniotomy with anterior temporal lobectomy, and median sternotomy with ventricular fibrillation to facilitate aneurysm clipping. An open-chest procedure allowed for application of AC (alternating current) electric shock directly to the heart to induce ventricular fibrillation, a useful tech- 


\section{Cardiac standstill and circulatory arrest in aneurysm surgery}

nique in the setting of premature aneurysm rupture or imminent aneurysm clipping. It was argued that due to complete vascular collapse upon cardiac arrest, the cerebral vessels were maximally decompressed allowing for optimal manipulation and clipping in treating aneurysms of the circle of Willis. Manual cardiac massage, sodium bicarbonate, and then DC (direct current) were used to convert the heart back to sinus rhythm. The length of ventricular fibrillatory arrest ranged from 1 minute to 28 minutes, with an average time of 9 minutes. Two operative deaths occurred. The patients in the later group had more favorable functional outcomes with 3 patients returning to work without neurological deficit. ${ }^{15}$ McMurtry subsequently used hypothermia and circulatory arrest on 17 occasions in the treatment of 60 basilar artery aneurysm without problems with perfusion pressure disturbances, sludging, or coagulopathies. ${ }^{14}$

In 1988, Robert F. Spetzler and colleagues from the Barrow Neurological Institute published an analysis of profound hypothermia with complete circulatory arrest and barbiturates for cerebral protection in the treatment of complex giant basilar artery aneurysms (Fig. 7). ${ }^{20}$ The group commented on the numerous technical microsurgical advantages of circulatory arrest for treatment of complex giant intracranial aneurysms. They specifically noted the improved visualization of dome anatomy and

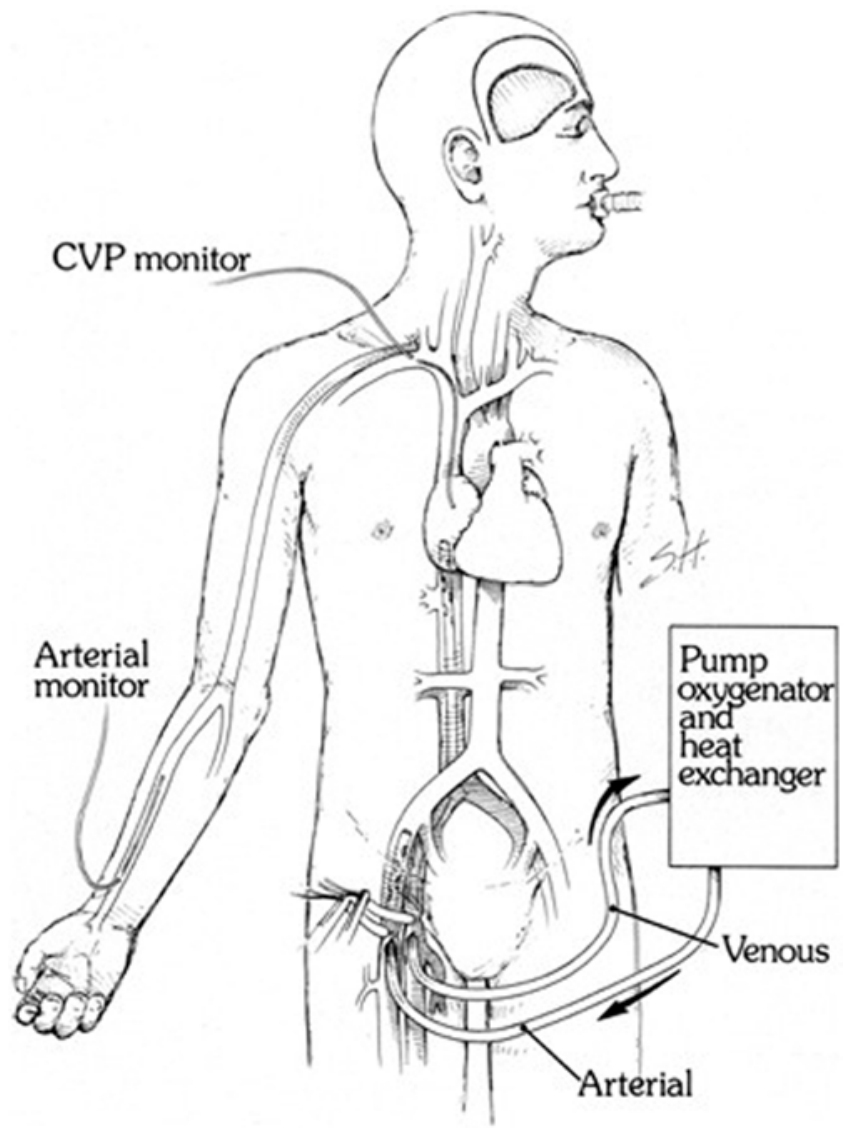

FIG. 7. Artist's representation of a patient prepared for extracorporeal circulation and induced hypothermia. CVP = central venous pressure. Reproduced with permission from Spetzler et al: $J$ Neurosurg 68:868-879, 1988. vascular perforators and the decreased risk of rupture during dissection. They described 4 key variables that determined the success of neurosurgical procedures that used circulatory arrest and profound hypothermia: depth of hypothermia, duration of total circulatory arrest, barbiturate use, and hemostasis. In this series, the total time range of effective circulatory arrest was 7 to 53 minutes.

In 1998, Michael Lawton from UCSF (University of California, San Francisco) School of Medicine and Barrow Neurological Institute published one of the largest modern experiences with complete hypothermic circulatory arrest for surgical treatment of intracranial aneurysms. The study was performed over a 12 -year period and included 60 patients who underwent 62 circulatory arrest procedures, predominantly for the treatment of posterior circulation aneurysms. As a result of their experience, the authors concluded that hypothermic circulatory arrest would be indicated only for giant aneurysms or posterior circulation aneurysms that could not be treated with conventional techniques or for patients in whom endovascular therapy was unsuccessful. ${ }^{10,20}$

\section{Adenosine-Induced Cardiac Standstill}

In 1999, Michael Groff and colleagues from Mt. Sinai School of Medicine published the first case report on adenosine-induced cardiac standstill and complete circulatory flow arrest for the clipping of an intracranial aneurysm with a good result (Figs. 8-10). ${ }^{7}$ Similar reports soon followed, ${ }^{16}$ and a series of cases from Helsinki University was published in 2009. ${ }^{13}$ The study reviewed 16 cases of adenosine use during intraoperative rupture. The cases involved 9 aneurysms located in the anterior circulation and 7 in the posterior circulation. Both the clipping and restoration

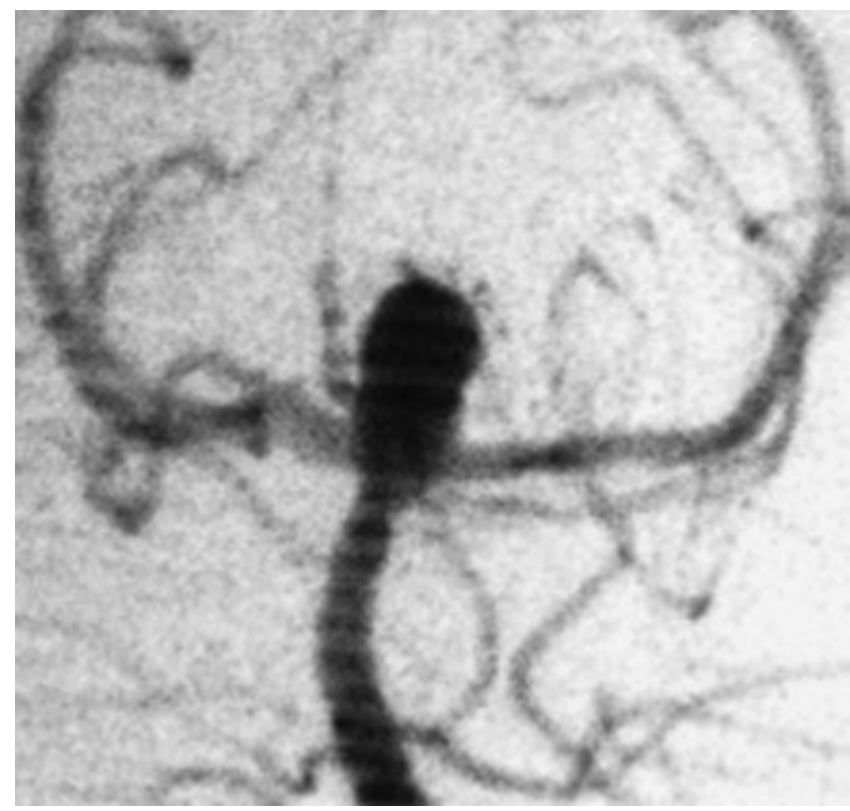

Fig. 8. Preoperative angiogram showing an aneurysm of the basilar artery. This was the first intracranial aneurysm treated by surgical clipping in the setting of adenosine-induced circulatory flow arrest. Reproduced with permission from Groff et al: J Neurosurg 91:687-690, 1999. 


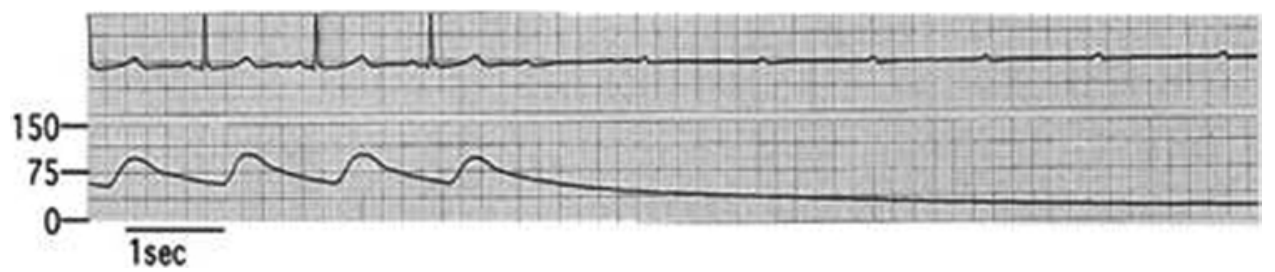

Fig. 9. Intraoperative electrocardiogram following adenosine infusion, showing the onset of asystole. Reproduced with permission from Groff et al: J Neurosurg 91:687-690, 1999.

of systemic circulation were successful in all cases. The authors noted no immediate or late adverse events related to administration of adenosine. They concluded that circulatory arrest by use of adenosine did not seem to have a deleterious effect on patient outcome. Furthermore, the authors deemed it safe to use during surgery for those patients who experienced sudden intraoperative rupture with uncontrollable bleeding and no evidence of preexisting cardiac conduction abnormalities..$^{13}$

In 2010, Guinn and colleagues performed a retrospective review of outcomes and complications associated with the use of adenosine for clipping of primarily anterior circulation aneurysms. In this series, 27 cases were examined; all 27 patients underwent successful clipping. The authors concluded that the duration of hypotension, not necessarily asystole, was the single most important factor for adequate clip placement using this technique. ${ }^{8}$ One serious complication during this study in one patient who experienced prolonged hypotension secondary to pulseless electrical activity required chemical intervention and cardiopulmonary resuscitation to reverse. The complication in this case was attributed to rapid redosing of adenosine without allowing for return of a normal hemodynamic profile between boluses. Rapid redosing was necessary due to intraoperative rupture and ensuing blood loss. All other cases were uncomplicated. The authors of this study emphasized that great care must be taken in the patient-selection process, as patients with significant atherosclerotic disease may have adverse outcomes. ${ }^{8}$

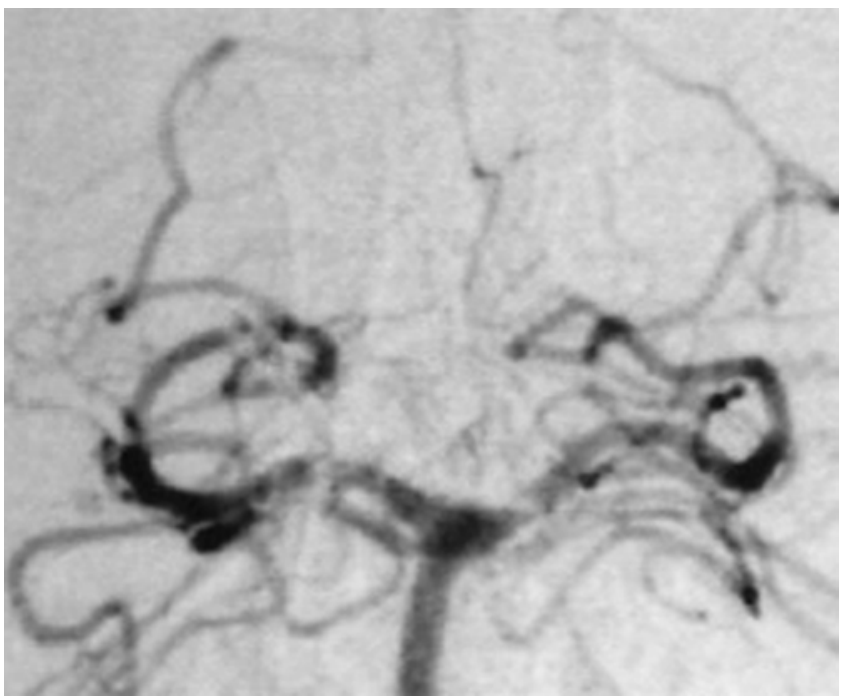

FIG. 10. Postoperative angiogram showing successful obliteration of the aneurysm. Reproduced with permission from Groff et al: $J$ Neurosurg 91:687-690, 1999.
Since the first case report describing use of adenosine for circulatory flow arrest, one of the issues precluding widespread implementation has been the lack of dose-response data. In 2010, Powers and colleagues used the individualized dose-response curve method recommended by Hashimoto to determine the proper dose to administer prior to aneurysm clipping in 6 patients. ${ }^{18}$ In response to this work, Bebawy and colleagues developed a weight-based dosing regimen to provide adequate hypotension and arrest, especially in cases in which the need for circulatory flow arrest was unanticipated. The study itself was conducted with the primary goal of determining this specific dose-response relationship and the rates of associated negative side effects. ${ }^{1}$ The authors concluded that a dose of $0.3-0.4 \mathrm{mg} / \mathrm{kg}$ ideal body weight provided adequate circulatory flow arrest of approximately 45 seconds with minimal rates of complications. ${ }^{1}$ They also concluded that the use of adenosine is a viable option for flow arrest in place of temporary occlusion for technically complex lesions with a low risk of neurological and cardiopulmonary morbidity. ${ }^{1}$

In 2011, a single-center retrospective review was published by Bendok and colleagues, describing 40 cases in which adenosine was used for the purpose of temporary flow arrest for clip ligation of both ruptured and unruptured aneurysms. The investigators used a bolus dose of $0.3-0.4 \mathrm{mg} / \mathrm{kg}$ ideal body weight, as previously recommended by Bebawy and colleagues. Of 40 patients, 19 required only 1 dose for securement, 16 required 2 doses, and 5 patients required 3 total doses. In 35 of 40 cases, the aneurysms were successfully clipped with this method (87.5\%). Transient arrhythmias were noted in 5 patients, but none were clinically significant. ${ }^{2}$ Upon completion of their review, the authors determined that the benefits of adenosine for temporary flow arrest far outweigh the risks. They also determined that use of adenosine works very well when operating in a narrow surgical field, where the placement of temporary occlusive clips may be technically difficult or may further limit exposure. There were no obvious clinically significant complications attributed to the use of adenosine in this series, and short-term follow-up demonstrated good neurological outcomes without adverse effects. The authors suggested that, while temporary flow clips remain the gold standard, adenosine should be considered an additional and possibly synergistic tool for aneurysm surgery. ${ }^{2}$

These reports have led to a general acceptance of adenosine as an adjunct in the surgical treatment of large or complex aneurysms, particularly in the posterior fossa (Fig. 11). Data on the use of adenosine to induce a transient circulatory flow arrest indicate that it is a safe and 


\section{Cardiac standstill and circulatory arrest in aneurysm surgery}
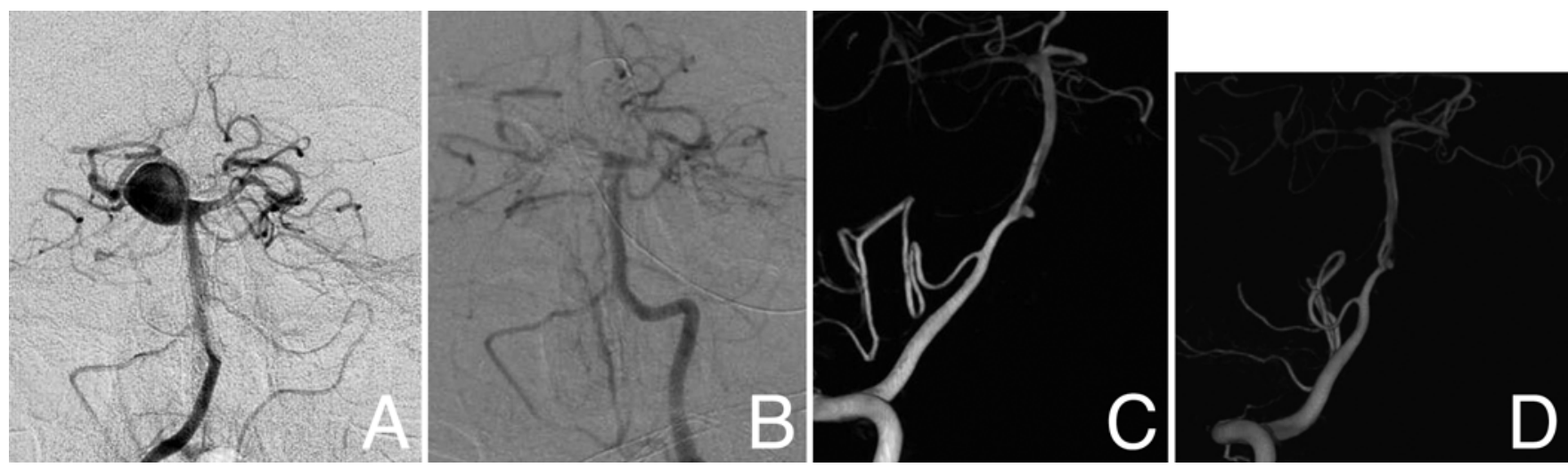

FIG. 11. Cerebral angiograms demonstrating types of cases in which adenosine-induced cardiac standstill may be helpful in aneurysm treatment. Large right superior cerebellar artery (A) aneurysm treated via an orbitozygomatic craniotomy. Intraoperative rupture was ultimately controlled with adenosine administration resulting in aneurysm softening and final clip application with a good angiographic result (B). Aneurysms arising from the vertebrobasilar junction also may require adenosine administration if the contralateral vertebral artery is patent. This aneurysm (C and $\mathbf{D})$, approached via a far-lateral craniotomy, was only clippable after adenosine-mediated cardiac standstill resulted in proximal control followed by clip occlusion.

potentially very useful adjunct for the treatment of complex intracranial aneurysms and those that have previously ruptured or rupture intraoperatively. Given appropriate patient selection, the drug has a very limited side effect profile, undergoes rapid in vivo degradation, and may be easily titrated to the desired effect. When compared with the known complications and possible adverse outcomes associated with cardiopulmonary bypass and hypothermic circulatory arrest, including coagulopathy, hyperglycemia, or rebound hyperthermia, the use of adenosine is markedly safer and less physiologically challenging. ${ }^{17}$

\section{Conclusions}

The use of cardiopulmonary bypass and induced hypothermia in the treatment of complex cerebral aneurysms, although of historical interest, has been supplanted by pharmacological substitutes. The use of adenosine in a cohesive team approach has been shown to have an acceptable risk profile and may provide benefit to those patients with aneurysms deemed too dangerous or unstable to be managed surgically with conventional methods.

\section{Disclosure}

The authors report no conflict of interest concerning the materials or methods used in this study or the findings specified in this paper.

Author contributions to the study and manuscript preparation include the following. Conception and design: Wright, Huang. Acquisition of data: Wright, Huang, Dabb. Analysis and interpretation of data: Wright, Sharma, Manjila, Xu, Dabb. Drafting the article: Bambakidis, Wright, Huang, Sharma, Manjila. Critically revising the article: Bambakidis, Wright. Reviewed submitted version of manuscript: Bambakidis. Approved the final version of the manuscript on behalf of all authors: Bambakidis. Administrative/ technical/material support: Bambakidis, Wright, Huang, Manjila.

\section{References}

1. Bebawy JF, Gupta DK, Bendok BR, Hemmer LB, Zeeni C, Avram MJ, et al: Adenosine-induced flow arrest to facilitate intracranial aneurysm clip ligation: dose-response data and safety profile. Anesth Analg 110:1406-1411, 2010
2. Bendok BR, Gupta DK, Rahme RJ, Eddleman CS, Adel JG, Sherma AK, et al: Adenosine for temporary flow arrest during intracranial aneurysm surgery: a single center retrospective review. Neurosurgery 69:815-821, 2010

3. Botterell EH, Lougheed WM, Morley TP, Vandewater SL: Hypothermia in the surgical treatment of ruptured in tracranial aneurysms. J Neurosurg 15:4-18, 1958

4. Drake CG, Barr HWK, Coles JC, Gergely NF: The use of extracorporeal circulation and profound hypothermia in the treatment of ruptured intracranial aneurysm. J Neurosurg 21: 575-581, 1964

5. Drew CE: Profound hypothermia in cardiac surgery. Br Med Bull 17:37-42, 1961

6. Gissen AJ, Matteo RS, Housepian EM, Bowman FO Jr: Elective circulatory arrest during neurosurgery for basilar artery aneurysms. JAMA 207:1315-1318, 1969

7. Groff MW, Adams DC, Kahn RA, Kumbar UM, Yang BY, Bederson JB: Adenosine-induced transient asystole for management of a basilar artery aneurysm. Case report. J Neurosurg 91:687-690, 1999

8. Guinn NR, McDonagh DL, Borel CO, Wright DR, Zomorodi AR, Powers CJ, et al: Adenosine-induced transient asystole for intracranial aneurysm surgery: a retrospective review. J Neurosurg Anesthesiol 23:35-40, 2011

9. Housepian EM, Bowman FO Jr, Gissen AJ: Elective circulatory arrest in intracranial surgery. Successful treatment of an aneurysm of the basilar artery with a method of open-chest circulatory arrest. J Neurosurg 26:594-597, 1967

10. Lawton MT, Raudzens PA, Zabramski JM, Spetzler RF: Hypothermic circulatory arrest in neurovascular surgery: evolving indications and predictors of patient outcome. Neurosurgery 43:10-21, 1998

11. Lougheed WM, Kahn DS: Circumvention of anoxia during arrest of cerebral circulation for intracranial surgery. $\mathbf{J}$ Neurosurg 12:226-239, 1955

12. Lougheed WM, Sweet WH, White JC, Brewster WR: The use of hypothermia in surgical treatment of cerebral vascular lesions. A preliminary report. J Neurosurg 12:240-255, 1955

13. Luostarinen T, Takala RS, Niemi TT, Katila AJ, Niemelä M, Hernesniemi J, et al: Adenosine-induced cardiac arrest during intraoperative cerebral aneurysm rupture. World Neurosurg 73:79-83, 2010

14. McMurtry JG III: Management of difficult basilar artery aneurysms. J Neurosurg 70:503-504, 1989 (Letter)

15. McMurtry JG III, Housepian EM, Bowman FO Jr, Matteo RS: Surgical treatment of basilar artery aneurysms. Elective circu- 


\section{J. M. Wright et al.}

latory arrest with thoracotomy in 12 cases. J Neurosurg 40: 486-494, 1974

16. Nussbaum ES, Sebring LA, Ostanny I, Nelson WB: Transient cardiac standstill induced by adenosine in the management of intraoperative aneurysmal rupture: technical case report. Neurosurgery 47:240-243, 2000

17. Ponce FA, Spetzler RF, Han PP, Wait SD, Killory BD, Nakaji P, et al: Cardiac standstill for cerebral aneurysms in 103 patients: an update on the experience at the Barrow Neurological Institute. Clinical article. J Neurosurg 114:877-884, 2011

18. Powers CJ, Wright DR, McDonagh DL, Borel CO, Zomorodi AR, Britz GW: Transient adenosine-induced asystole during the surgical treatment of anterior circulation cerebral aneurysms: technical note. Neurosurgery 67 (2 Suppl Operative): 461-470, 2010

19. Spencer FC, Bahnson HT: The present role of hypothermia in cardiac surgery. Circulation 26:292-300, 1962
20. Spetzler RF, Hadley MN, Rigamonti D, Carter LP, Raudzens PA, Shedd SA, et al: Aneurysms of the basilar artery treated with circulatory arrest, hypothermia, and barbiturate cerebral protection. J Neurosurg 68:868-879, 1988

21. Todd NV, Howie JE, Miller JD: Norman Dott's contribution to aneurysm surgery. J Neurol Neurosurg Psychiatry 53:455458,1990

Manuscript submitted Deccember 13, 2013.

Accepted February 7, 2014.

Please include this information when citing this paper: DOI: 10.3171/2014.2.FOCUS13554.

Address correspondence to: Nicholas C. Bambakidis, M.D., Department of Neurological Surgery, University Hospitals Case Medical Center, 11100 Euclid Ave., Cleveland, OH 44106. email: Nicholas.Bambakidis2@UHhospitals.org. 